\title{
La perversión de la ayuda estadounidense: el Congreso de Estados Unidos y la crisis de los Mirage peruanos ${ }^{1}$
}

\author{
Norberto Barreto Velázquez²
}

Recibido: 5 de noviembre de 2018 / Aceptado: 4 de octubre de 2019

Resumen. Un grupo de congresistas estadounidenses usaron la compra de cazas franceses Mirage por el gobierno peruano en 1967, para atacar dos elementos claves de la política estadounidense durante la guerra fría: la ayuda económica y la asistencia militar. Sus críticas se enmarcaron dentro del debate sobre la naturaleza de la ayuda exterior estadounidense que se venía desarrollando desde el surgimiento de ésta a finales de los años 1940. Estos legisladores cuestionaron la utilidad de la ayuda económica, criticaron las prioridades de los países receptores de ésta y recalcaron el impacto negativo de la ayuda militar. Las acciones del gobierno peruano jugaron así un importante papel en el desarrollo de las relaciones entre el Ejecutivo y el poder legislativo estadounidenses en un momento crítico de la historia de Estados Unidos.

Palabras clave: Ayuda económica; asistencia militar; carrera armamentista; Perú; Estados Unidos; siglo XX.

\section{[en] The Perversion of American Aid: The Congress of the United States and the Peruvian Mirage Crisis}

\begin{abstract}
A group of American congressmen used the Peruvian government's purchase of French Mirage fighter planes in 1967 to attack two key elements of the United States' Cold War policy: economic aid and military assistance. Their criticism was framed within the debate over the nature of US foreign aid, as it had developed since its emergence towards the end of the 1940's. The legislators questioned the usefulness of the economic aid and criticized the priorities of the recipient countries. They also highlighted the negative impact of military assistance. The actions of the Peruvian government, therefore, played an important role in the development of relations between the American Executive and Legislative powers in a critical moment of United States history.
\end{abstract}

Keywords: Economic aid; military assistance; arms race; Peru; United States; $20^{\text {th }}$ Century.

Sumario. 1. Introducción. 2. El Congreso y la historiografía. 3. El Congreso y la ayuda exterior. 4. La compra de los Mirage. 5. El Congreso y los Mirage. 6. Después de la crisis. 7. Conclusión. 8. Referencias bibliográficas.

Cómo citar: Barreto Velázquez, N. (2020) La perversión de la ayuda estadounidense: el Congreso de Estados Unidos y crisis de los Mirage peruanos, en Revista Complutense de Historia de América 46, 219-237.

\footnotetext{
1 El autor agradece a Giancarlo S. Mori Bolo y a los evaluadores anónimos de la revista por su valiosa ayuda en la elaboración de este trabajo.

2 Universidad del Pacífico (Perú)

Email: barreto_n@up.edu.pe
} 


\section{Introducción}

El 21 de junio de 1967, el Senador Wayne L. Morse (Republicano (R)-Oregón) introdujo en el libro de actas del Congreso estadounidense un editorial del diario The Washington Post titulado "Shakedown in Peru", criticando duramente la compra, por el gobierno peruano, de doce cazas supersónicos franceses Mirage $5 s$ por 28 millones de dólares. Para el editorialista, tal gasto era imperdonable para un país que en 1966 registró un déficit de $\$ 160$ millones y que, además, pretendía recibir préstamos del gobierno estadounidense para cubrir sus problemas de déficit presupuestario. El diario estadounidense consideraba la compra de los cazas franceses un acto irresponsable que, además, podría desencadenar una carrera armamentista en América Latina ${ }^{3}$.

Morse, quien era Presidente del Subcomité de Asuntos Latinoamericanos, aprovechó la ocasión para dirigirse al pleno del Senado. El Senador consideraba, que la posible concesión de préstamos a Perú, sería una perversión del programa de asistencia económica estadounidense. Para Morse era totalmente inaceptable ayudar al Perú a lidiar con sus problemas presupuestarios justo cuando el país sudamericano se embarcaba en una carrera armamentista a expensas de los contribuyentes estadounidenses. El Republicano consideraba que las autoridades peruanas debían invertir dinero en mejorar las condiciones de vida de sus masas empobrecidas "y no en mantener el prestigio de la oligarquía militar"4.

Con sus comentarios Morse vinculó de forma directa la compra de los Mirage con dos elementos claves de la política exterior estadounidense: la asistencia económica y la ayuda militar. Para el Senador, el mal uso de la ayuda exterior estaba fomentando el militarismo, claramente expresado en la compra de los cazas franceses. Como el editorialista del Washington Post, el legislador consideraba que la compra de los Mirage desencadenaría una carrera armamentista entre los países sudamericanos, de la cual la ayuda económica y militar estadounidense sería indirectamente responsable.

Las palabras del Senador Morse destacan un elemento no explorado en el análisis de una de las crisis más importantes en las relaciones peruano-estadounidenses: el papel que jugó la compra de los Mirage en los debates congresionales sobre el futuro de la ayuda económica y militar de Estados Unidos. La discusión que se desató en el Congreso estadounidense alrededor del tema de los Mirage se enmarcó dentro de un debate mayor que giraba en torno a dos preguntas: ¿Cuán eficientes eran los programas de ayuda exterior? ¿Cuán necesarios eran? Este no era un debate nuevo, pues la ayuda económica había estado en discusión desde su inicio con el Plan Marshall en 1947. Es necesario señalar que tal discusión había sufrido altas y bajas, y que la década de 1960 fue testigo de un renacer de tal debate caracterizado por una fuerte participación congresional. En esos años varios legisladores cuestionaron de forma directa, desde diferentes orientaciones ideológicas y políticas, la ayuda económica y militar brindada por Estados Unidos en el mundo.

Este ensayo analizará el papel que jugó la polémica en torno a la compra de los Mirage dentro de la discusión legislativa sobre la ayuda exterior estadounidense. La compra de los cazas franceses provocó una fuerte reacción entre los miembros del Congreso, quienes se mostraron molestos e indignados por las acciones del gobierno

Congressional Record (en adelante CR), $90^{\text {th }}$ Cong., $1^{\text {st }}$ sess., June 21, 1967, 16601-16602.

"And not to maintain the prestige of a military oligarchy". Ibídem, 16601. Traducido por el autor. 
peruano. Planteamos que la reacción de un grupo de legisladores ante la compra de los Mirage estuvo determinada por la discusión sobre la naturaleza y utilidad de los programas de ayuda exterior del gobierno estadounidense. En otras palabras, éstos usaron la discusión en torno a los Mirage para cuestionar y atacar los programas de ayuda económica y militar. Su posición fue principalmente ideológica, no partidista; y se enmarcó en el debate sobre la naturaleza del programa de asistencia del gobierno estadounidense que como ya señalamos, se venía desarrollando desde sus mismos comienzos a mediados de la década de 1940.

El tema de los Mirage nos ofrece una gran oportunidad para analizar cómo un grupo de congresistas estadounidenses usó una crisis en las relaciones bilaterales con un país latinoamericano para adelantar sus agendas políticas e ideológicas en un momento clave de la historia de Estados Unidos ${ }^{5}$. De igual forma, nos permitirá entender el papel que jugaron las acciones del gobierno peruano en el desarrollo de las relaciones entre las ramas del gobierno estadounidense finales de la década de 1960.

El caso peruano brinda a los legisladores opuestos a la ayuda económica un excelente ejemplo del alegado mal uso ésta. El caso de los Mirage les permite preguntar por qué un país receptor de asistencia podía a la vez adquirir armas costosas y sofisticadas. ¿Si las prioridades del gobierno del Perú no eran con el bienestar de su población, sino en el armamento, ¿por qué Estados Unidos debía invertir el dinero de sus contribuyentes en la prosperidad de los peruanos?

Para analizar las discusiones legislativas de la compra de aviones los Mirage usaremos como fuente principal, el libro de sesiones del Congreso estadounidense (Congressional Record). Esta importante fuente documental, poco usada en el análisis de las relaciones de América Latina y Estados Unidos, contiene las transcripciones de las discusiones y comentarios de los legisladores durante las sesiones legislativas, tanto de la Cámara de Representantes como del Senado.

\section{El Congreso y la historiografía}

Los historiadores peruanos han prestado poca atención a las relaciones entre Perú y Estados Unidos. Prueba de ello es que, con muy pocas excepciones, los principales trabajos publicados sobre ese tema han sido producidos por investigadores estadounidenses. Entre ellos podemos mencionar las publicaciones de Paul Gootenberg, Richard J. Walter, Lawrence A. Clayton, Sewall H. Menzel, Fredrick B. Pike, Daniel A. Sharp, Cynthia McClintock, Abraham F. Lowenthal y James C. Carey, entre otros ${ }^{6}$.

5 La década de 1960 es uno de los periodos más complejos en la historia estadounidense. A nivel interno, Estados Unidos experimentó en una serie de procesos sociales, políticos y culturales que transformaron su sociedad. Los afroamericanos exigieron la igualdad social y política, los jóvenes se rebelaron contra las normas sociales y la sociedad de consumo, las mujeres reclamaran la igualdad de género, los homosexuales se organizaron en defensa de sus derechos, y los latinos y amerindios se rebelaron contra la marginación. A nivel internacional, Estados Unidos se involucró en un conflicto bélico en el Sudeste Asiático que dañó la credibilidad, economía y consenso social de la nación estadounidense. La revolución cubana retó la hegemonía norteamericana sobre América Latina, complicando la Guerra Fría. Este accidentado periodo histórico culminó con una profunda crisis política - consecuencia de la derrota en Vietnam y el futuro escándalo de Watergate- que afectó duramente la confianza del pueblo estadounidense en su gobierno y sus líderes. Ver: Dallek, 1998; Patterson, 1996; Gitlin, 1987; Matusow, 1984.

$6 \quad$ Walter, 2010; Gootenberg, 2008; Clayton, 1999; Menzel, 1996; McClintock - Lowenthal, 1983; Pike, 1977; Sharp, 1972; Carey, 1964. 
Es justo señalar que los académicos peruanos no han estado del todo ausentes del análisis de las relaciones entre ambos países. Aunque recientemente varios analistas peruanos han prestado atención a las relaciones bilaterales desde diferentes ángulos, hay temas que han sido ignorados o tratados muy superficialmente ${ }^{7}$.

Quienes han estudiado las relaciones peruano-estadounidenses han concentrado sus esfuerzos en analizar el papel que ha jugado el poder ejecutivo del gobierno estadounidense en el desarrollo de éstas. Al enfocar las acciones del Presidente, del Secretario de Estado, de la Armada o de los embajadores, han ignorado la influencia de la rama legislativa en la formulación de la política exterior estadounidense. A pesar de los poderes que le confiere la Constitución estadounidense sobre la política exterior -aprobación de fondos, ratificación de tratados internacionales, aprobación de restricciones legislativas a las acciones del poder ejecutivo, y supervisión y evaluación la política exterior de los Estados Unidos- el Congreso estadounidense tampoco ocupa un papel en el estudio de las relaciones de Estados Unidos y América Latina proporcional a su relevancia e influencia ${ }^{8}$. Esto no quiere decir que el Congreso haya sido totalmente ignorado por los historiadores, sino que ha ocupado un papel secundario con relación al poder ejecutivo.

Este problema no se limita al análisis de las relaciones de Estados Unidos con América Latina o el Perú. Según Julian E. Zelizer, uno de los principales estudiosos del Congreso, los historiadores estadounidense han prestado poca atención a la rama legislativa del gobierno norteamericano. Además, sus enfoques han sido muy estrechos, pues han minimizado la importancia e influencia del Congreso ${ }^{9}$. Aunque Zelizer reconoce los avances en el estudio del Congreso, concluye que éste sigue siendo un campo poco explorado ${ }^{10}$.

A través del estudio del papel que jugó el tema de los Mirage en la discusión en torno a la ayuda exterior estadounidense, este ensayo buscar aportar, tanto al análisis del rol del poder legislativo en la política exterior estadounidense, como al desarrollo de la historiografía de las relaciones peruano-estadounidenses.

\section{El Congreso y la ayuda exterior}

Según Carol Lancaster, el programa de ayuda económica estadounidense es un producto de la guerra fría que se inaugura con la asistencia brindada a Grecia y Turquía en $1947^{11}$. Ante la incapacidad de los británicos para seguir apoyando a los griegos en su lucha contra una insurgencia comunista y a los turcos frente a la presión soviética, el Presidente Harry S. Truman convenció a un Congreso fiscalmente conservador, a asignar $\$ 400$ millones de ayuda para ambos países ${ }^{12}$. Un año más tarde fue

\footnotetext{
Ver por ejemplo Laguerre, 2015; Contreras, 2010; Romero, 2008.

Barreto, 2016; McKercher, 2014.

Zelizer, 2000.

10 Los historiadores Gary Stone, Robert D. Johnson y Paul C. Milazzo han hecho aportaciones significativas al análisis del Congreso. Ver Stone, 2007; Johnson, 2006; Milazzo, 2006.

11 Lancaster, 2007: 5. Es necesario mencionar como antecedentes históricos del programa de ayuda a la Comisión de Socorro de Bélgica (1914-1915), la Administración de Alimentos (US Food Administration, 1917), la Administración de Ayuda Estadounidense (American Relief Administration, 1918), la Ley de Préstamo y Arriendo (Lend-Lease Act, 1941) y el programa de ayuda a los países ocupados tras la segunda guerra mundial (Government and Relief in Occupied Areas, 1944-1947. Sanahuja, 1999: 13-14.

12 Lancaster, 2007: 66.
} 
creado el Plan Marshall a través de la Ley de Cooperación Económica. La Administración de Cooperación Económica (Economic Cooperation Administration, ECA), encargada de administrar el PM y "la primera agencia especializada de ayuda", jugó un papel clave en la reconstrucción de los países europeos después de la segunda guerra mundial ${ }^{13}$.

Truman también logró apoyo congresional para un programa de ayuda técnica para países subdesarrollados conocido como el Punto Cuarto ${ }^{14}$. Para administrar el Punto Cuarto fue creada en 1950, la Administración de Cooperación Técnica (Technical Cooperation Administration, TCA). Esto provocó una situación confusa, pues la administración Truman tenía dos "instrumentos legales y dos agencias de ayuda": TCA y ECA. En algunos países en desarrollo TCA era la encargada de la ayuda técnica. En otros países, ECA era responsable de los créditos y las donaciones. Para solucionar este problema fue aprobada en 1951 la Ley de Seguridad Mutua (Mutual Security Act, MSA), integrando todas "las modalidades de ayuda en un solo marco legal", inclusive la militar ${ }^{15}$.

De acuerdo con José Antonio Sanahuja, la aprobación de la MSA significó dos innovaciones significativas: la creación del Fondo Económico para la Defensa (Defense Economic Fund) y el establecimiento de la Agencia de Seguridad Mutua (Mutual Security Agency, MSA). El primero provenía de los Fondos de Apoyo Económico (Economic Support Funds). La segunda era una "entidad administradora" adscrita al Departamento de Estado, que funcionó entre 1951 y 1953. Esta fue sustituida por la Administración de Operaciones Exteriores (Foreign Operations Administration), que fue a su vez remplazada por la Administración de Cooperación Internacional (International Cooperation Administration, ICA).

ICA estuvo "encargada de los programas de seguridad mutua" hasta 1961, cuando el Congreso aprobó la Ley de Asistencia Exterior (Foreign Assistance Act) en respuesta a nuevos retos internacionales (revolución cubana, descolonización de África, etc. $)^{16}$. La administración Kennedy buscaba expandir y unificar el programa de ayuda para fortalecer el tema del desarrollo ${ }^{17}$. Esta ley sustituyó a la MSA e hizo del desarrollo económico y social uno de los principales objetivos del programa de ayuda económica ${ }^{18}$. Para administrar los programas de ayuda económica fue creada, en sustitución de ICA, la Agencia de los Estados Unidos para el Desarrollo Internacional (United States Agency for International Development, USAID) ${ }^{19}$.

El apoyo congresional a la ayuda económica tuvo sus altas y bajas. En los primeros años de la posguerra, la oposición a la asistencia económica estuvo dirigida por legisladores conservadores preocupados por los costos. El programa de ayuda económica sobrevivió gracias al apoyo de una coalición bipartidista compuesta por Demócratas del norte y Republicanos moderados, unidos por la guerra fría ${ }^{20}$. Según

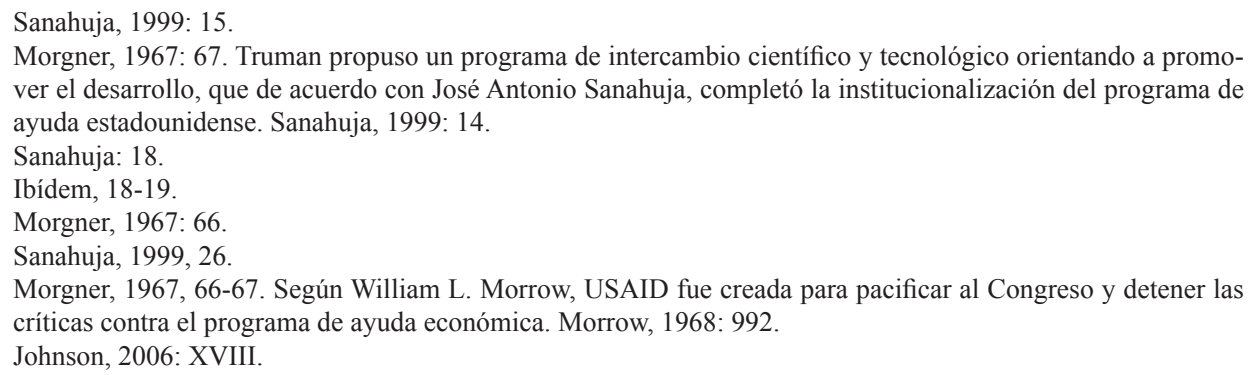


los historiadores David Holm y Andrew David, este consenso comenzó a resquebrajarse antes de que Estados Unidos se involucrara en la guerra de Vietnam, pues el programa comenzó a ser atacado en el Congreso a principios de los años $1960^{21}$. David y Holm enfatizan el efecto que tuvo el fin del consenso de la guerra fría en lo que el Congreso estaba dispuesto hacer para oponerse al comunismo ${ }^{22}$. Según estos autores, los congresistas le fueron perdiendo entusiasmo al programa de ayuda porque no entendían cuál era su propósito, es decir, cómo servía a los intereses nacionales estadounidenses. Además, tomaron conciencia del tiempo y dinero que requería completar los proyectos de ayuda ${ }^{23}$.

Para el economista Aurelius Morgner, el programa había creado unas expectativas que no cumplió, especialmente, en términos políticos. El Congreso -y el pueblo estadounidense- esperaban que el crecimiento económico que debía generar el programa produjera gobiernos democráticos, estables y amigables hacia Estados Unidos. Por eso, cada golpe de estado y cada demostración anti-estadounidense en un país subdesarrollado se veía como un fracaso del programa ${ }^{24}$.

Robert David Johnson, por su parte, concentra su análisis en un grupo de congresistas a quienes identifica como los disidentes liberales. Legisladores como Frank Church (Demócrata (D)-Idaho), Wayne L. Morse (Republicano (R)-Oregón), Albert Gore (D-Tennessee), Ernest R. Gruening (D-Alaska) y George McGovern (D-Dakota del Sur) cuestionaron la ayuda económica asignada a gobiernos dictatoriales sólo porque eran anticomunistas. Estos propusieron enmiendas negando la ayuda económica a gobiernos que hubiesen llegado al poder por medios no democráticos ${ }^{25}$.

Por las razones que fuese, es claro que, para principios de la década de 1960, el Congreso comenzó a cuestionar la necesidad y utilidad del programa de ayuda económica. Las crecientes críticas congresales coincidieron con la cruzada anticomunista de Kennedy. Sus dos principales programas - la contrainsurgencia y la Alianza para el Progreso- requerían aumentos significativos en la ayuda económica y militar que debían ser aprobados por el Congreso. Conseguir el apoyo congresal para la Alianza no fue fácil, especialmente por la oposición del representante conservador Otto E. Passman (D-Luisiana), presidente del Comité de Operaciones Extranjeras de la Cámara de Representantes. Para Passman, la ayuda exterior era un desperdicio de dinero, por lo que usó su poder para sabotearla, retrasando el proceso de aprobación legislativa ${ }^{26}$. Según Taffet, Kennedy estuvo en constante conflicto con un Congreso reacio a invertir dinero en su programa de ayuda, y perdió de forma consistente ${ }^{27}$. Ya para 1962, los críticos del programa comenzaron a quejarse de la alegada lentitud de USAID y de los pocos resultados alcanzados. Ese año el Congreso redujo en un $18 \%$ del presupuesto de asistencia presentado por la administración Kennedy ${ }^{28}$.

\footnotetext{
21 David - Holm, 2016: 85-86. Según Lancaster, sin los imperativos de la guerra fría, el programa de ayuda económica se habría reducido o eliminado una vez finalizado el Plan Marshall. Lancaster, 2007: 65.

22 David - Holm, 2016: 85.

23 Ibídem, 67.

24 Morgner, 1967: 67.

25 Johnson, 2006: XVIII.

26 Passman era quien decidía qué proyectos de ley pasaban a ser discutidos en el pleno de la Cámara y era, además, una figura clave en las negociaciones con el Senado. Taffet, 2007: 40-41. David - Holm, 2016: 67.

27 Según Taffet, Johnson fue más exitoso evitando que el Congreso redujera su propuesta de ayuda, pidiendo menos dinero que Kennedy. Taffet, 2007: 39 y 41.

28 Ver Tabla 1. Según Lancaster, los principales opositores eran congresistas conservadores. Lancaster, $2007: 71$.
} 
En 1963 Kennedy enfrentó la llamada foreign aid revolt. Bajo el liderato Passman y el apoyo de los disidentes liberales, el Congreso redujo en un 34\% el presupuesto de ayuda económica de la administración Kennedy ${ }^{29}$. Los congresistas también enmendaron el proyecto de ley de ayuda económica, imponiendo limitaciones a la concesión de ésta. Con esta victoria congresional se inició lo que Johnson denomina como una nueva era en las relaciones entre los poderes ejecutivo y legislativo ${ }^{30}$.

La guerra de Vietnam también llevó al Congreso a jugar un papel más activo en elaboración y discusión de la política exterior estadounidense. Un grupo creciente de congresistas criticó la participación estadounidense en el conflicto indochino. Estos consideraban que la guerra fría había llevado al gobierno estadounidense a apoyar regímenes dictatoriales en beneficio de intereses estratégicos y a expensas de los ideales tradicionales estadounidenses. Criticaban que Estados Unidos dependiera de soluciones militares para problemas que eran claramente políticos ${ }^{31}$.

La oposición a la ayuda económica y a la guerra de Vietnam provocó un proceso de creciente disidencia legislativa. Esta disidencia no se limitó a estos dos temas, pues también surgieron voces críticas de otros asuntos como la ayuda militar ${ }^{32}$. Cuando las autoridades peruanas deciden retar a la administración de Lyndon B. Johnson comprándole cazas al gobierno francés, las relaciones entre los poderes ejecutivo y legislativo eran ya tensas. La compra de los Mirage vino a complicar el escenario y les brindó a los enemigos de la ayuda externa una excelente oportunidad para criticarle y cuestionarle.

\section{La compra de los Mirage}

A mediados de la década de 1960, la mayoría de las fuerzas aéreas latinoamericanas se encontraban en condiciones lamentables con aviones viejos o incapaces de volar. Esto llevó a que varias naciones suramericanas buscaran modernizar su capacidad aérea comprando aviones supersónicos ${ }^{33}$. En los años 1950 el gobierno de Dwight D. Eisenhower había animado a los vecinos hemisféricos a fortalecerse militarmente para que pudieran aportar a la defensa regional. Gracias al Programa de Asistencia Militar (PAM) los latinoamericanos podían adquirir armamento estadounidense en condiciones financieras generosas ${ }^{34}$. La llegada de Kennedy a la Casa Blanca y el inicio de la Alianza para el Progreso trajeron cambios en la política del gobierno de Estados Unidos. Kennedy buscaba impulsar el desarrollo económico de América Latina para frenar el virus revolucionario cubano, por lo que promovió que sus vecinos meridionales invirtieran en la adquisición de armas diseñadas para la seguridad interna y la lucha contrainsurgente, dejando fuera la adquisición de armas convencionales de mayor costo como los cazas supersónicos. Cuando en 1963 varios países sudamericanos buscaron modernizar sus fuerzas aéreas con cazas estadounidenses, la administración Kennedy se negó a venderlos, alegando que éstos no eran los más

\footnotetext{
29 Kennedy solicitó \$4.5 mil millones en ayuda económica y el Congreso sólo aprobó \$3.0 mil millones. Ver Morrow, 1968: 987; Foreign AID, 1963.

30 Johnson, 2006: 104.

Ibídem: XIX.

Ibídem.

Masterson, 1991: 221.

Le Roy, 2002: 270-271.
} 
apropiados para las necesidades militares de América Latina ${ }^{35}$. Según el historiador francés François Le Roy, las autoridades estadounidenses también recurrieron a un argumento que enfatizaba las necesidades básicas de los gobiernos de la región; es decir, a cuestionar sus prioridades de forma paternalista. Para funcionarios como Teodoro Moscoso, Coordinador de la Alianza para el Progreso, el dinero gastado en la compra de aviones de combate podría ser usado para construir escuelas, graduar ingenieros, y proveer leche a miles de niños ${ }^{36}$. Ninguno de estos argumentos convenció a los latinoamericanos, quienes siguieron insistiendo en la necesidad de modernizar sus fuerzas aéreas, aun cuando ello conllevara problemas con Estados Unidos.

A pesar de que Lyndon B. Johnson no tenía mayores problemas con la adquisición de aviones supersónicos, su llegada a la presidencia no marcó un cambio en la política de su predecesor porque, según Le Roy, tenía que prestar atención a la oposición de un grupo de congresistas liberales, quienes consideraban que, además de promover una peligrosa carrera armamentista, el PAM desperdiciaba los impuestos pagados por los estadounidenses y aumentaba el peligro de golpes de estado en América Latina ${ }^{37}$. La preocupación de Johnson por la posible reacción del Congreso es un indicio del nivel de conflictividad existente entre los poderes ejecutivo y legislativo.

En 1965 el gobierno estadounidense vendió a la Argentina aviones Douglas A-4 Skyhawks para evitar que los militares derrocaran al gobierno de Arturo Illia ${ }^{38}$. La compra de los aviones no sólo no salvó a Illia que igual fue derrocado por los militares, sino que generó una reacción en cadena en la región. Los primeros en reaccionar fueron los chilenos quienes buscaron comprar cazas británicos lo que a su vez provocó que los peruanos indicaran su deseo de adquirir Match-two jets ${ }^{39}$.

Según Le Roy, los legisladores liberales pidieron a Johnson que hiciera todo lo que estuviera a su alcance pata disuadir a Perú de adquirir aviones supersónicos y éste buscó a aplacar a los peruanos ofreciéndoles F86-Sabres usados, un avión subsónico que se había hecho famoso durante la guerra de Corea. Los peruanos rechazaron la oferta, reiterando su deseo de adquirir aviones supersónicos Northrop F-5 Freedom Fighters. En su discurso del quinto aniversario de la Alianza para el Progreso en agosto de 1966, el Presidente pidió a los líderes latinoamericanos "que evitaran los costos de adquirir y mantener equipo militar innecesario en desmedro de la ropa, comida y educación de nuestros niños" ${ }^{\text {"40 }}$. Johnson volvió a la carga durante la Conferencia de Punta del Este en abril de 1967, pero no consiguió que los líderes latinoamericanos firmaran una declaración comprometiéndose a no comprar aviones supersónicos. Ante esta negativa, Johnson optó por prohibirle a la compañía Northrop venderle aviones $F 5$ a las naciones latinoamericanas y pidió a sus aliados no venderles aviones similares a los militares latinoamericanos. Los británicos

\footnotetext{
Ibídem: 271.

Ibídem: 272.

37 Ibídem: 273. Romero coincide con LeRoy en la disponibilidad de la administración Johnson a vender a aviones supersónicos, posición que no compartía el Congreso. Romero, 2008: 111.

38 Masterson, 1991: 221.

39 Le Roy, 2002: 273. Aviones capaces de "volar a una velocidad dos veces superior a la del sonido". Fernández, 1975: 191. Según Contreras, fue la compra por Chile de 21 cazas británicos Hawker Hunters, lo que llevó a los militares peruanos a querer adquirir los F5. La negativa estadounidense causó resentimiento entre los peruanos, quien cuestionaron la dependencia del Perú en Estados Unidos. Contreras, 2010: 224

$40 \quad$ "To find a way to avoid the cost of procuring and maintaining unnecessary military equipment that will take clothes off the back and food away from the stomach and education away from the minds of our children". Le Roy, 2002: 277. Traducción del autor.
} 
aceptaron a regañadientes, los franceses no ${ }^{41}$. En mayo de 1967, el gobierno peruano acordó con su homólogo francés la compra de doce aviones supersónicos Mirage $5 \mathrm{~s}$, venta que se formalizó el 4 de octubre de 1967 por 28 millones de dólares ${ }^{42}$.

Las posibles consecuencias de la compra de los Mirage alarmaron a la administración Johnson, especialmente, por la posible reacción del Congreso. A Johnson le preocupaba el futuro del proyecto de ley de ayuda económica de 1968, ya que la Cámara de Representantes había aprobado su versión del proyecto por sólo ocho votos $\mathrm{y}$, por ende, podría fracasar si solo un pequeño grupo de legisladores liberales cambiaban su voto cuando fuese considerado en conferencia bicameral ${ }^{43}$. Según Le Roy, Johnson enfrentaba problemas ante la creciente oposición a la guerra de Vietnam, por lo que consideraba inaceptable una derrota en su patio trasero. Sin embargo, eran pocas sus opciones, especialmente, porque sólo la venta de los $F 5$ podría convencer a los peruanos de no comprar los Mirage, pero ello hubiese significado problemas con el Congreso ${ }^{44}$.

Temerosa de que se afectara su influencia en América Latina, la administración Johnson buscó retomar la iniciativa vendiéndole a Perú los $F 5$ que originalmente le había negado. El problema estaba en el Congreso, dada la oposición a algunos miembros de los subcomités de asuntos latinoamericanos tanto del Senado como de la Cámara de Representantes. Según Le Roy, congresistas como James William Fulbright (D-Arkansas), Thomas E. Morgan (D-Pennsylvania), Frank Church (D-Idaho) y Wayne L. Morse (R-Oregon) eran críticos abiertos de la política de Johnson en Vietnam y no se sentían inclinados a favorecerle ${ }^{45}$. La administración Johnson alegó que no venderle los aviones a Perú favorecía a Francia a expensas de Estados Unidos, quien perdería influencia entre los militares latinoamericanos. También rechazó las acusaciones de que la venta de los F5 reforzaría el militarismo peruano y alegó que, por el contrario, ésta fortalecería la posición del presidente peruano Fernando Belaúnde Terry ante la creciente agitación militar ${ }^{46}$. A pesar de sus esfuerzos, los funcionarios de la administración Johnson no lograron convencer a miembros de los subcomités de asuntos latinoamericanos. A pesar de ello, la administración optó por la ofrecerle los aviones a Perú junto a un préstamo de $\$ 40$ millones condicionado a deshacer el acuerdo de compra de los Mirage, propuesta que fue rechazada por el gobierno peruano ${ }^{47}$.

Como refleja la Tabla 1, los temores de Johnson sobre el futuro del proyecto de ley de ayuda económica para 1968 no eran infundados. En 1967, la administración Johnson solicitó 3.2 mil millones de dólares para el programa de ayuda y el Congreso aprobó 2.3 mil millones, un recorte de $29 \%$. Este corte era el mayor registrado desde la foreign aid revolt de 1963. Un año más tarde, el gobierno solicitó \$2,918,500,000 en ayuda económica y el Congreso sólo aprobó \$1,974,050,000, un recorte de 11\%. Este era el

41 Ibídem: 278

42 Ibídem: 279-280.

43 Ambas cámaras legislativas tienen que aprobar una versión idéntica de cada proyecto de ley. Las diferencias poco importantes se revuelven a través de consultas informales. De existir puntos de vista encontrados, se recurre a un comité conjunto conocido como el Comité de Conferencia. Sus miembros buscan reconciliar las diferencias, pero de no lograrlo el proyecto de ley no es aprobado. Pérez Espinosa, 2014: 120-121.

44 Le Roy, 2002: 283.

45 Ibídem: 285.

46 Ibídem: 286.

47 Ibídem. 
presupuesto más pequeño en la historia del programa de ayuda económica ${ }^{48}$. Con estos recortes al presupuesto, el Congreso ejerció uno de sus principales poderes sobre la política exterior estadounidense, el llamado power of the purse $e^{49}$. La serias reducciones en los presupuestos de ayuda económica para 1968 y 1969 reflejan el nivel de conflictividad entre los poderes ejecutivo y legislativos con relación al tema de la asistencia.

Tabla. 1. Cortes en el presupuesto de ayuda económica, 1961-196750.

\begin{tabular}{|c|c|c|c|}
\hline Año & Pedido $^{\text {51 }}$ & Aprobado $^{\mathbf{5 2}}$ & \% Recorte \\
\hline 1961 & 4.8 & 3.9 & 18 \\
\hline 1962 & 4.8 & 3.9 & 18 \\
\hline 1963 & 4.5 & 3.0 & 34 \\
\hline 1964 & 3.5 & 3.3 & 8 \\
\hline 1965 & 3.5 & 3.2 & 7 \\
\hline 1966 & 3.4 & 2.9 & 13 \\
\hline 1967 & 3.2 & 2.3 & 29 \\
\hline
\end{tabular}

No podríamos terminar esta sección sin responder a una pregunta: ¿qué ocurrió con los Mirage? Según el historiador peruano Alberto Fernández Prada Effio, los cazas franceses llegaron a Perú en junio de 1968 y tras ser ensamblados por técnicos galos, aterrizaron en Lima el 19 de julio de 1968, donde participaron en las celebraciones del día de la independencia peruana, el 28 de julio $^{53}$. Ese día los peruanos pudieron echarle un ojo a la costosa manzana de la discordia con el gobierno estadounidense. En respuesta a la consumación de la compra de los Mirage, la administración Johnson aplicó la enmienda Symington - de la cual hablaremos más adelante- reteniendo préstamos que estaban destinados al gobierno peruano por un total de $\$ 37.5$ millones. Esto provocó una gran indignación y una fuerte reacción nacionalista en el Perú, por lo que se consideraba una intromisión indebida en los asuntos internos peruanos ${ }^{54}$.

\section{El Congreso y los Mirage}

Es claro del análisis de Le Roy que el Congreso jugó un papel muy importante durante la crisis provocada por la venta de los Mirage. Cabe preguntarse, ¿qué provocó

\footnotetext{
48 A la AP se le recortaron \$200 millones, dejándole con un presupuesto de \$420 millones. Congress Clears, 1969.

49 Barreto, 2016: 81.

50 Esta tabla es una versión abreviada en una similar que forma parte de Morrow, 1968: 987.

51 En miles de millones de dólares.

52 Ibídem.

53 Fernández Prada, 1974: 190.

54 Le Roy, 2002: 292-293. Según Romero, la crisis de los Mirage provocó que las relaciones entre los militares peruanos y EEUU “se echaron a perder". Romero: 114. Para Contreras, con la compra de los Mirage, Perú cuestionó la hegemonía hemisférica estadounidense. Contreras, 2010: 224.
} 
tal interés y preocupación de parte de los legisladores? Para el historiador francés la clave está en la guerra de Vietnam. Según Le Roy, la venta de los Mirage dio a los legisladores opositores del conflicto indochino "un medio para desafiar la política exterior del gobierno sin poner en peligro las vidas de los soldados estadounidenses ni levantar dudas sobre su patriotismo"

A pesar de su importancia indiscutible, la guerra de Vietnam no es el único ni el más importante factor necesario para entender la actitud del Congreso durante la crisis provocada por la compra de los Mirage $e^{56}$. La reacción de los congresistas ante la compra de los cazas franceses se enmarca en el desarrollo de la actitud congresal con relación a dos elementos claves de la política exterior estadounidense de la posguerra: la ayuda económica y la ayuda militar. El programa de ayuda económica enfrentó los recelos congresales desde su arranque con el Plan Marshall, pero pudo sobrevivir gracias al apoyo bipartidista. El escepticismo congresional creció durante década de 1960, y llevó a la foreign aid revolt de 1963, ya comentada anteriormen$\mathrm{t}^{57}$. Tanto conservadores como liberales criticaron ambos rubros de la política exterior estadounidense. Los conservadores se quejaban de los costos de la ayuda económica y de la tendencia a dar ayuda a gobiernos cuyas políticas eran poco amistosas con los intereses de negocios estadounidenses. Los liberales, por su parte, atacaron duramente la ayuda militar y económica otorgada a gobiernos no democráticos ${ }^{58}$.

La compra de los Mirage -armas costosas y sofisticadas, cuya utilidad y necesidad podían ser claramente cuestionadas- por un país receptor de ayuda tanto militar como económica, generó una situación perfecta para atacar ambos programas. Un grupo de congresistas -Demócratas y Republicanos- usó la crisis de los Mirage para cuestionar la utilidad de la ayuda económica, criticar las prioridades de los países receptores de ésta y subrayar el alegado impacto político negativo de la asistencia militar. Por ejemplo, en julio de 1967, el Representante John B. Anderson (R-Illinois) se opuso a un proyecto de ley enmendando la ley que creó el Banco Interamericano de Desarrollo (BID) usando al Perú como argumento. El proyecto de ley buscaba aumentar los fondos del BID para operaciones especiales, lo que Anderson consideraba un error. Para justificar su posición, el congresista les recordó a sus colegas que Perú pronto adquiriría aviones supersónicos franceses. Según él, esto demostraba que aumentar los fondos del BID haría más fácil el mal uso de la ayuda económica en la compra de armas sofisticadas por países latinoamericanos ${ }^{59}$. En palabras de Anderson, "Me pregunto si no tenemos problemas en nuestras manos que deberían tener mayor prioridad que hacer posible a países latinoamericanos negociar con vendedores de armas la compra de cazabombarderos Mirage y de otras armas de guerra caras y sofisticadas" ${ }^{\circ 0}$.

55 "A means to challenge the administration's foreign policy without endangering the lives of U.S. soldiers and casting doubt on their own patriotism". Ibídem: 283. Traducción del autor.

56 No encontramos ninguna referencia directa a la guerra de Vietnam entre los planteamientos de los legisladores que criticaron la compra de los Mirage.

57 Ver nota número 6.

58 Johnson, 2006: 92.

59 CR, 90 ${ }^{\text {th }}$ Cong., $1^{\text {st }}$ sess., July 26, 1967, 20212-20213. El Representante William B. Widnall (R-New Jersey) apoyó las expresiones de Anderson. Ibídem: 20216.

60 "I wonder if we do not have problems on our own hands that ought to have a little bit higher priority than making it possible for Latin American countries to go out and deal with the arms brokers and buy Mirage jet bombers and all of the expensive and sophisticated weapons of war". Ibídem: 20213. Traducción del autor. 
Uno de los congresistas más activos en el debate en torno a los Mirage lo fue el Senador Morse (R-Oregón), quien en octubre de 1967 acusó a Perú de haber tratado de chantajear a Estados Unidos ${ }^{61}$. Morse, quien era Presidente del Subcomité de Asuntos Latinoamericanos del Senado, rechazó cualquier intento de aumentar los impuestos por la administración Johnson y le sugirió al gobierno economizar dinero reduciendo el número de divisiones militares desplegadas en Europa y dejando de apoyar económicamente a la Argentina y al Perú. Ambos países habían recibido ayuda económica por sus problemas económicos, pero esto no había evitado que Perú, un país con un ingreso per cápita de menos de \$200, comprara cazas a Francia. Compra que se había dado porque los peruanos no habían podido chantajear a Estados Unidos para que le vendiese aviones supersónicos. Para Morse era claro que si los peruanos querían adquirir aviones de otros países, las autoridades estadounidenses debían "dejarlos también buscar en otra parte su ayuda económica"62.

Morse no fue el único legislador que propuso el uso de la ayuda como un arma para presionar o castigar al Perú por la compra de los Mirage. Reaccionando a la decisión del gobierno de venderle los cazas $F 5$ a Perú, el Representante Henry S. Reuss (D-Wisconsin) propuso reducir la ayuda económica como herramienta para combatir la adquisición de armas sofisticadas en América Latina ${ }^{63}$. El Senador Frank Church (D-Idaho) creía que los países latinoamericanos eran libres de adquirir armamento a expensas de otras necesidades, pero tendrían que aceptar las consecuencias de sus actos. Church fue uno de los miembros más destacados de los disidentes liberales. Durante su larga permanencia en el Senado (1957-1981), fue una de las voces más críticas de la política exterior de Estados Unidos, especialmente, en Indochina y América Latina ${ }^{64}$. Tras el rechazo peruano a la oferta de los cazas F5, el Senador preguntaba cínicamente cuál sería la posición del Departamento de Estado con relación a la ayuda económica para el Perú, ya que no se podía justificar si procedía la compra de los Mirage, pero sí lo estaba si Perú hubiese aceptado los Northrop F-5. Según Church, Estados Unidos debía prevenir una carrera armamentista en el hemisferio occidental, enviando un mensaje claro al Perú: si compras cazas franceses, que sea Francia, entonces, quien te de ayuda económica. Esto revitalizaría a la Alianza para el Progreso, le ahorraría dinero a los estadounidenses y mejoraría la imagen Estados Unidos en América Latina ${ }^{65}$.

Morse asimismo toca el tema de la Alianza para el Progreso. Según el Senador, con la compra de los Mirage, el porcentaje del presupuesto peruano dedicado a la adquisición de armamento aumentaba de 14.7\% a 18.9\%. Justo cuando el Perú se embarcaba en una carrera armamentista, su gobierno había solicitado ayuda económica para cuadrar su presupuesto. De haber sido concedida esta ayuda, los contribuyentes estadounidenses habrían avalado indirectamente la carrera armamentista peruana, cuando era claro que el Perú debía estar invirtiendo su dinero en mejorar las condi-

61 Morse, uno de los disidentes liberales, ocupó un escaño senatorial entre 1945 y 1969, destacándose por su independencia. Disponible en https://www.senate.gov/artandhistory/history/common/generic/Featured_Bio_Morse. htm.

${ }^{62}$ CR, $90^{\text {th }}$ Cong., $1^{\text {st }}$ sess., October 6, 1967: 28131. "let them elsewhere also to get their economic aid". Traducción del autor.

63 En palabras de Reuss, "la compra de armas debería tener un gran peso a la hora de determinar ayuda económica estadounidense". Ibídem, October 18, 1967: 29349. "arms should be weighed heavily in determining U.S. aid". Traducción del autor.

64 Schmitz ,1994: 561-565.

65 CR, 90 ${ }^{\text {th }}$ Cong., $1^{\text {st }}$ sess., October 26, 1967: 30131-30132. 
ciones de vida de sus masas, y no en su "oligarquía militar" ${ }^{\prime 6}$. De concretarse lo que el Senador catalogaba como una perversión de la ayuda económica estadounidense, "los propósitos originales de la Alianza para el Progreso quedarían anulados"67. Para Morse, la Alianza había perdido su inspiración y razón de ser, y había terminado convirtiéndose en un "frío mecanismo para la exportación de productos estadounidenses a América Latina", que solo beneficiaba a los $\operatorname{ricos}^{68}$. Morse también consideraba necesario reducir la ayuda militar a América Latina porque ésta estaba "arruinando a la Alianza para el Progreso" y sólo producía dictaduras y juntas militares ${ }^{69}$.

Church también ataca al programa de ayuda militar, subrayando la necesidad de una revisión a fondo de éste. En un largo discurso pronunciado el 26 de junio de 1967, el Senador planteaba que el programa de ayuda militar no servía a los intereses nacionales estadounidenses. Según Church, desde 1950, Estados Unidos había otorgado ayuda militar por un total de $\$ 37$ mil millones. A esto habría que añadirle varios miles de millones de dólares en venta de armas. Cerca de 12,000 estadounidenses estaban asignados a brindar asesoría, entrenamiento y supervisión militar en más de 35 países $^{70}$. De esta forma se habían desperdiciado miles de millones de dólares que pudieron ser usados para promover el desarrollo, estimular el crecimiento económico y mejorar las condiciones de vida de multitudes. Con la excusa de frenar el comunismo, la ayuda militar estadounidense había exacerbado conflictos regionales en Asia (Paquistán-India) y Europa (Grecia-Turquía) ${ }^{71}$. La ayuda militar tampoco ayudaba a mantener la estabilidad interna de los países subdesarrollados que la recibían. Por el contrario, ésta había llevado a la destrucción de gobiernos legítimos y su sustitución por dictaduras militares en Asia, África y América Latina. Todo ello llevaba a Church a concluir que era necesario eliminar la mayoría de las subvenciones militares y reducir la entrega de $\operatorname{armas}^{72}$. En cuanto a la venta de armas, Church no se oponía las transacciones con países ricos, pero creía que no se le debían vender armas a regiones conflictivas ${ }^{73}$. Church critica duramente la venta innecesaria de los cazas Douglas A-4 a Argentina porque ésta había generado una reacción en cadena por parte de sus vecinos que terminó con la compra peruana de los Mirage. Concluía que el peligro de una carrera armamentista en América Latina sería el resultado de la ayuda militar estadounidense ${ }^{74}$.

Los Senadores Joseph S. Clark (D-Pennsylvania) y Stephen M. Young (D-Ohio) reaccionan a los comentarios de Church subrayando el peligro de que la compra de los Mirage provocara una carrera armamentista suramericana. Para Clark, el peligro estaba en que se podrían exacerbar en los problemas fronterizos entre Perú y Chile.

66 Ibídem, June 21, 1967: 16601. Traducción del autor.

${ }^{67}$ "The Alliance for Progress will be as dead as a doornail, insofar as its original purposes are concerned”. Ibídem. Traducción del autor.

68 "Cold mechanism for moving American commodities into Latin America". Ibídem. Traducción del autor.

69 "Bespoling our Alliance for Progress program”. Ibídem. Traducción del autor. Morse también se oponía al envío de asesores militares a América Latina. Ibídem, October 18, 1967: 29272.

70 Ibídem, June 26, 1967: 17306.

71 Ibídem: 17307.

72 Ibídem: 17308.

73 Ibídem: 17309.

74 Ibídem. El Representante Clarence D. Long (D-Marylad) también criticó el programa de ayuda militar y usó al Perú, entre otros casos, como ejemplo. Long criticó que un país como Perú que había recibido \$18 millones en ayuda militar en 1966 y que tenía una deuda con Estados Unidos de \$200 millones, pudiese comprar cazas supersónicos franceses. Ibídem, August 22, 1967, 23605. 
Young temía que otras naciones latinoamericanas también quisieran adquirir cazas supersónicos ${ }^{75}$. Young y Clark no eran los únicos a quienes preocupaba el posible inicio de una carrera armamentista. El Representante Henry S. Reuss (D-Wisconsin) criticaba la venta de los Northrop F-5 a países latinoamericanos porque no eran relevantes en la lucha anti-guerrillera y sólo buscaban realzar el prestigio de los militares latinoamericanos. El Representante Robert L. Legget (D-California) también se manifestó preocupado por el peligro de una carrera armamentista en América Latina, destacando el papel de Francia como suplidor de armas. Para Legget, era necesario tomar medidas para disuadir a quienes promovían esta carrera armamentista, pero no sugiere nada en específico. Tanto Reuss como Legget consideraban la compra de armas sofisticadas un desperdicio de recursos que podían ser usados promover los intereses económicos y sociales de América Latina ${ }^{76}$.

Reaccionando a la decisión del gobierno estadounidense de venderle cazas F5 a Perú, el Congresista William B. Widnall (R-New Jersey) hizo referencia a los problemas en las relaciones franco-estadounidenses ${ }^{77}$. Para evitar una carrera armamentista Widnall proponía adoptar una cuota hemisférica para la compra de armas. Sólo así se podría seguir justificando ante los contribuyentes estadounidense la aportación económica a la Alianza para el Progreso, al BID y al Banco Mundial. De no lograrse tal cuota, el aporte estadounidense debía ser reducido drásticamente o terminado ${ }^{78}$.

Es necesario señalar que, en el caso de los Mirage, el Congreso no se limitó a criticar, sino que tomó medidas concretas con la aprobación de dos enmiendas a la Ley de Asistencia Extranjera de 1961. La primera enmienda -la Symington (1967)obligaba al presidente a suspender la ayuda económica a cualquier país que usara fondos de la ayuda militar para adquirir armas sofisticadas. La segunda enmienda -la Conte-Long (1968) - suspendía los préstamos para desarrollo a cualquier país que tuviera gastos militares que pudieran afectar negativamente su desarrollo económico $\mathrm{y}$, por ende, considerados como "innecesarios" por el Congreso ${ }^{79}$.

\section{Después de la crisis}

El uso de los Mirage por miembros del Congreso no terminó con la adquisición de los cazas por el gobierno peruano. Hemos encontrado referencias a la compra de los cazas franceses en un periodo que va de 1968 a 1975. Por ejemplo, a finales de mayo de 1968, el Representante Clarence D. Long (D-Maryland) comentaba el significado de la aprobación de la enmienda que en unión al Representante Silvio L. Conte (RMassachusetts) había presentado y que mencionamos al cierre de la sección previa. Para el Demócrata, con la aprobación de la enmienda Conte-Long el Congreso le había hecho claro a los países subdesarrollados que eran libres de gastar su dinero,

75 Ibídem: 17310; October 18, 1967, 29275; October 26, 1967, A5266-5267; November 6, 1967: 29275; 52665267; 31383-31-384.

76 Ibídem, October 26, 1967, A5266-5267; November 6, 1967: 31383-31384.

77 Tras su regreso al poder en 1958, el General Charles de Gaulle desarrolló una política exterior que buscaba restaurar la autoridad e independencia de Francia, especialmente, con relación a sus aliados occidentales. El nacionalismo del presidente galo afectó negativamente las relaciones con Estados Unidos. LaFeber, 1989: vol. 2,560 .

78 CR, 90st Cong., $1^{\text {st }}$ sess., October 18, 1967, 29275.

79 Romero, 2008: 61. 
pero no el de los Estados Unidos. Perú había sido el primer país en sentir los efectos de la enmienda como consecuencia de la compra de los Mirage. Según Long, el New York Times informaba que el gobierno de Perú estaba furioso y que inclusive algunos peruanos amenazaban con expropiar empresas privadas estadounidenses en respuesta $^{80}$. Esto confirmaba las sospechas de Long de que las naciones subdesarrolladas creían que tenían derecho a recibir ayuda económica estadounidense independientemente de qué hicieran con el dinero o qué realmente estuvieran buscando promover su desarrollo económico y los niveles de vida de sus pueblos ${ }^{81}$. Para Long, la compra de los Mirage tenían poco que ver con la lucha contra la subversión comunista. Lo que querían los militares peruanos era estar preparados para enfrentar a Chile, un país aliado de Estados Unidos que había recibido una cantidad considerable de ayuda económica estadounidense ${ }^{82}$. Long criticaba que la autoestima de los generales peruanos estuviera por encima de las necesidades de millones de niños y adultos hambrientos en el Perú. El legislador cerró su alocución proponiendo que la enmienda Long-Conte fueran endurecida, pero no especificó cómo ${ }^{83}$.

El Representante Conte también se manifestó preocupado por la venta de armas sofisticadas a países subdesarrollados que, según él, no estaban en condiciones de desperdiciar así sus recursos. El 4 de junio de 1968, el legislador republicano introdujo en el libro de actas del Congreso, un editorial del New York Times apoyando la suspensión de la de ayuda económica al Perú en respuesta a la compra de los Mi$r_{\text {rage }}{ }^{84}$. Dos años más tarde, Conte retomó el tema de los Mirage al criticar el papel de Estados Unidos en el desarrollo de lo que el congresista denominaba como "a jet club in Latin America". Los comentarios de Conte implicaban que el temor congresal a una carrera armamentista se había hecho realidad, ya que alegaba que, como consecuencia de la compra de los cazas franceses, otros países latinoamericanos habían adquirido o querían adquirir aviones similares. Para Conte, el culpable de ello era el gobierno estadounidense, es decir, el poder ejecutivo ${ }^{85}$.

Las críticas contra la compra de los Mirage continuaron en la década de 1970. Por ejemplo, en febrero de 1973, el Representante John S. Monangan (D-Connecticut)

80 Long hace referencia a un artículo escrito por Malcon W. Browne titulado "Peruvians Angry Over U.S. Aid Ban-Decision to Buy Jets from France Widely Defended". En su escrito, Browne señalaba que la aplicación de la enmienda Conte-Long y la consiguiente suspensión de la ayuda económica estadounidense (development loans) provocó una unidad poco común entre los peruanos. Prácticamente todas las facciones política -desde la izquierda radical hasta oficiales del gobierno de Belaunde- denunciaron públicamente las acciones del gobierno estadounidense. De acuerdo con el periodista estadounidense, el presidente del Partido Demócrata Cristiano, Héctor Cornejo, había presentado una moción en el Senado peruano para expropiar empresas estadounidenses en respuesta a la aplicación de la enmienda Conte-Long al Perú. Aunque la moción fue rechazada por el Senado peruano, las críticas continuaron al punto que el Premier y Ministro de Relaciones Exteriores, Raúl Ferrero Rebagliati, sugirió plantearle al gobierno de Estados Unidos, que gastara en el bienestar de los pueblos asiáticos o de los pobres estadounidenses, lo que estaba gastando en la guerra de Vietnam. CR, 90st Cong., 2nd sess., May $27,1968,15209$.

81 Ibídem.

82 Ibídem, 15210.

83 Ibídem. En septiembre de 1968, el Representante Thomas E. Morgan (D-Pennsylvania) criticó la política estadounidense con relación a la venta de armas y usó, entre otros factores, la compra de lo Mirage como ejemplo. Ibídem, September 10, 1968, 26217.

${ }_{84}$ Ibídem, June 4, 1968, 15979. En enero de 1968, Conte introdujo en el libro de actas un artículo publicado en el Washington Post titulado "Latin Decisions to Buy Jets Could Trigger Arms Race", criticando duramente la carrera armamentista desatada en América Latina tras la compra de los Mirage.

85 De acuerdo con Conte, "los peruanos necesitan cazas tanto como yo necesito un hueco en mi cabeza". Ibídem, June 4, 1970, 18402. “The Peruvians need jets like I need a hole in my head”. Traducción del autor 
criticó la venta de armas a naciones extranjeras. Según el Congresista, había dos posiciones con relación a este tema: aquellos que consideraban que la venta de armas fomentaba carreras armamentistas y represión; mientras que otros consideraban que era mejor vender las armas y evitar así que los países las adquirieran de manos de otros suplidores. De acuerdo con Monangan, este debate se había intensificado con la reciente adquisición de armas por Perú, Brasil y Argentina ${ }^{86}$.

La última referencia a los Mirage que hemos encontrado fue en setiembre de 1975, cuando el Representante James G. Abourezk (D-South Dakota) introdujo en el récord legislativo un artículo del Michel T. Kline titulado "How to Trigger an Arms Race". Publicado por la revista The Nation, el escrito de Kline era una dura crítica a la venta de armas estadounidenses a países latinoamericanos. Los Mirage jugaron un papel importante en este proceso, pues según su autor, la compra de los cazas franceses llevó a otras naciones latinoamericanas a adquirir, en contra de la oposición estadounidense, estos aviones. Kline alega que la aplicación de la enmienda ConteLong llevó a algunos países a diversificar las fuentes de sus compras de armamento y a otros a desarrollar su propia industria armamentista. Todo ello en desmedro del control estadounidense de la venta de $\operatorname{armas}^{87}$.

Estas referencias directas e indirectas a la compra de los Mirage reflejan el impacto que las acciones del gobierno peruano tuvieron entre algunos miembros del Congreso. Para éstos, la adquisición de los Mirage reflejaba dos problemas de los programas de ayuda económica y militar: su mal uso y sus consecuencias imprevistas.

\section{Conclusiones}

La discusión congresional del tema de los Mirage formó parte y estuvo determinada por un asunto altamente controversial y espinoso, especialmente, en las relaciones del Congreso con el Ejecutivo: la discusión sobre la naturaleza y utilidad de los programas de asistencia exterior del gobierno estadounidense. Un grupo de congresistas aprovechó la oportunidad que generó la compra de los cazas franceses para cuestionar y atacar dos elementos claves de la política exterior estadounidense del periodo posterior al fin de la segunda guerra mundial: la ayuda económica y la asistencia militar. Su posición era ideológica - no partidista- y se enmarcaba en el debate sobre la naturaleza del programa de asistencia del gobierno estadounidense desarrollado desde sus mismos comienzos a mediados de la década de 1940. Estos legisladores cuestionaron la utilidad de la asistencia económica y recalcaron el impacto negativo de la ayuda militar. También criticaron las prioridades de los países receptores de ayuda económica al cuestionar la utilidad y necesidad de la compra de los Mirage, y la vieron como el resultado del militarismo que, según ellos, promovía el programa de asistencia militar estadounidense. Al invertir millones de dólares en aviones de combate, las autoridades peruanas habían actuado irresponsablemente, desatendiendo las necesidades urgentes de su pueblo. El gran temor de estos legisladores era que

86 CR, $91^{\text {st }}$ Cong., $2^{\text {nd }}$ sess., February 23, 1971, 29033. Monagan introdujo al libro de actas un artículo escrito por C. L. Zulzberger titulado "Arms and the French", publicado en el New York Times. Este artículo analizaba cómo los franceses habían sabido aprovechar la carrera armamentista latinoamericana y hacía alusión a la compra de los Mirage. Ibídem, 3639-3640.

87 CR, 94t $\mathrm{t}^{\mathrm{h}}$ Cong., $1^{\text {st }}$ sess., September 17, 1975, 29033. 
la compra de los Mirage desatara una carrera armamentista en América Latina, de la que Estados Unidos sería responsable, tanto directo como indirecto.

Las acciones del gobierno peruano jugaron un importante papel en el desarrollo de las tirantes relaciones entre el Ejecutivo y un poder legislativo cada vez más propenso a ejercer sus poderes constitucionales, cuestionando la política exterior estadounidense. Al retar a la administración Johnson, los peruanos abrieron una puerta que los enemigos de la ayuda exterior no dudaron en cruzar.

\section{Referencias bibliográficas}

Barreto Velázquez, Norberto. "El gran ausente: el Congreso estadounidense en el estudio de las relaciones entre América Latina y Estados Unidos". Huellas de Estados Unidos, vol. 11, (octubre 2016), 78-88. Disponible en: http://www.huellasdeeua.com/ediciones/ edicion11/08_Norberto_Barreto_Velazquez_78-88.pdf

Carey, James C. Peru and the United States, 1900-1962. Notre Dame: University of Notre Dame Press, 1964.

Clayton, Lawrence A. Peru and the United States: The Condor and the Eagle. Athens: University of Georgia Press, 1999.

Congress Clears. "Congress Clears Smallest Foreign Aid Bill in History". CQ Almanac 1968. Washington, D.C.: Congressional Quarterly, 1969. Disponible en http://library.cqpress. com/cqalmanac/cqal68-1284072

Congressional Record (United States Congress). Congressional Record. Proceedings and Debates of the $90^{\text {th }}$ Congress, First Session. Washington, D.C.: United States Government Printing Office, 1967.

- Congressional Record. Proceedings and Debates of the 90 $9{ }^{\mathrm{th}}$ Congress, Second Session. Washington, D.C.: United States Government Printing Office, 1968.

- Congressional Record. Proceedings and Debates of the $91{ }^{\text {th }}$ Congress, First Session. Washington, D.C.: United States Government Printing Office, 1969.

- Congressional Record. Proceedings and Debates of the 91 $9{ }^{\text {th }}$ Congress, Second Session. Washington, D.C.: United States Government Printing Office, 1970.

- Congressional Record. Proceedings and Debates of the $92^{\text {th }}$ Congress, First Session. Washington, D.C.: United States Government Printing Office, 1971.

- Congressional Record. Proceedings and Debates of the $94^{\text {th }}$ Congress, First Session. Washington, D.C.: United States Government Printing Office, 1975.

Contreras, Paulo C. "Struggle for Modernization: Peru and the United States, 1961-1968". Tesis Doctoral, University of Connecticut, 2010.

Dallek, Robert. Flawed Giant: Lyndon Johnson and His Times, 1961-1973. New York: Oxford University Press, 1998.

David, Andrew - Holm, Michael. "The Kennedy Administration and the Battle over Foreign Aid: The Untold Story of the Clay Committee". Diplomacy \& Statecraft, vol. 27. (2016), 65-92. DOI: https://doi.org/10.1080/09592296.2016.1137735

Fernández Prada Effio, Alberto. La aviación peruana, tercer tomo. Lima: Editorial Universo, 1975.

Foreign AID. "Foreign AID Program Suffers Setbacks". CQ Almanac 1963. Washington, D.C.: Congressional Quarterly,1964, 255-288. Disponible en http://ibrary.cqpress.com/ cqalmanac/cqal63-1317019

Gitlin, Todd. The Sixties: Years of Hope, Days of Rage. New York: Bantam Books, 1987. 
Gootenberg, Paul. Andean Cocaine: The Making of a Global Drug. North Carolina: The University of North Carolina Press, 2008.

Johnson, Robert David. Congress and the Cold War. New York: Cambridge University Press, 2006.

LaFeber, Walter. The American Age: U.S. Foreign Policy at Home at Abroad. New York London: W.W. Norton, 1989.

Laguerre Kleiman, Michel. El Oncenio y el desarrollo de la armada peruana (1919-1930). Lima: Dirección de Intereses Marinos, 2015.

Lancaster, Carol. Foreign Aid: Diplomacy, Development, domestic politics. Chicago: The University of Chicago Press, 2007.

Le Roy, Francois. "Mirage Over the Andes: Peru, France, the United States, and Military Jet Procurement in the 1960s". Pacific Historical Review, vol. 71 (2002), 269-300. DOI: https://doi.org/10.1525/phr.2002.71.2.269

Masterson, Daniel M. Militarism and Politics in Latin America: Peru from Sánchez Cerro to Sendero Luminoso. New York: Greenwood Press, 1991.

Matusow, Allen J. The Unravelling of America: The History of Liberalism in the 1960s. New York: Harper \& Row, 1984.

McClintock, Cynthia - Lowenthal, Abraham F. The Peruvian Experiment Reconsidered. Princeton: Princeton University Press, 1983.

McKercher, Asa. "Steamed Up: Domestic Politics, Congress, and Cuba, 1959-1963”. Diplomatic History, vol. 38 (2014), 599-627. DOI: https://doi.org/10.1093/dh/dht101

Menzel, Sewall H. Fire in the Andes: U. S. Foreign Policy and Cocaine Politics in Bolivia and Peru. Lanham: University Press of America, 1996.

Millazo, Paul C. Unlikely Environmentalists: Congress and Clean Water, 1945-1972. Kansas: Kansas University Press, 2006.

Morgner, Aurelius. "The American Foreign Aid Program: Costs, Accomplishments, Alternatives?". The Review of Politics, vol. 29 (1967), 65-75. DOI: https://doi.org/10.1017/ S0034670500023731

Morrow William L. "Legislative Control of Administrative Discretion: The Case of Congress and Foreign Aid". The Journal of Politics, vol. 30 (1968), 985-1011. DOI: https://doi. org/10.2307/2128685

Patterson, James C. Grand Expectations: The United States, 1945-1974. New York - Oxford: Oxford University Press, 1996.

Pérez Espinosa, César. El Congreso de Estados Unidos: pragmatismo y pluralismo. México: CISAN, 2014.

Pike, Fredrick B. The United States and the Andean Republics: Peru, Bolivia, and Ecuador. Cambridge: Harvard University Press, 1977.

Romero Sommer, Gonzalo. "Una amistad con enmiendas: las relaciones Perú-Estados Unidos 1963-1974”. Tesis de Maestría, Pontificia Universidad Católica del Perú, 2008.

Sanahuja, José Antonio. Ayuda económica y seguridad nacional: la ayuda externa de Estados Unidos, del Plan Marshall a la posguerra fría. Madrid: Entinema, 1999.

Schmitz, David F. - Fousakis, Natalie. "Frank Church, the Senate, and the Emergence of Dissent on the Vietnam War". Pacific Historical Review 63, 4 (1994), 561-565. DOI: https:// www.jstor.org/stable/3639949?seq=1\#metadata_info_tab_contents

Sharp Daniel A., (ed.). U.S. Foreign Policy and Peru. Austin and London: The Institute of Latin American Studies, The University of Texas Press, 1972.

Stone, Gary. Elites for Peace: The Senate and the Vietnam War, 1964-1968. Knoxville: University of Tennessee Press, 2007. 
Taffet, Jeffrey. Foreign Aid as Foreign Policy: The Alliance for Progress in Latin America. New York: Routledge, 2007.

Walter, Richard J. Peru and the United States, 1960-1975: How Their Ambassadors Managed Foreign Relations in a Turbulent Era. University Park: Pennsylvania State University Press, 2010.

Zelizer, Julian E. “Introduction to Roundtable”. Social Sciences History, vol. 24 (2000), 307316. DOI: https://doi.org/10.1017/S0145553200010142 